\title{
Extrafine triple therapy delays COPD clinically important deterioration vs ICS/LABA, LAMA, or LABA/LAMA
}

This article was published in the following Dove Medical Press journal: International Journal of COPD

\section{Dave Singh' \\ Leonardo M Fabbri ${ }^{2,3}$ \\ Stefano Vezzoli ${ }^{4}$ \\ Stefano Petruzzelli ${ }^{4}$ \\ Alberto Papi}

'Medicines Evaluation Unit, University of Manchester, Manchester University NHS Foundation Trust, Manchester, UK; ${ }^{2}$ Section of Cardiorespiratory and Internal Medicine, Department of Medical Sciences, University of Ferrara, Ferrara, Italy; ${ }^{3}$ COPD Center, Institute of Medicine, Sahlgrenska University Hospital, University of Gothenburg, Gothenburg, Sweden; ${ }^{4}$ Global Clinical Development, Chiesi Farmaceutici SpA, Parma, Italy
Correspondence: Dave Singh Medicines Evaluation Unit, University Hospital of South Manchester, University of Manchester, Southmoor Road, Manchester, M23 9QZ, UK

Tel +44 I6I 9464052

Email dsingh@meu.org.uk
Background: Current pharmacological therapies for COPD improve quality of life and symptoms and reduce exacerbations. Given the progressive nature of COPD, it is arguably more important to understand whether the available therapies are able to delay clinical deterioration; the concept of "clinically important deterioration" (CID) has therefore been developed. We evaluated the efficacy of the single-inhaler triple combination beclometasone dipropionate, formoterol fumarate, and glycopyrronium (BDP/FF/G), using data from three large 1-year studies.

Methods: The studies compared BDP/FF/G to BDP/FF (TRILOGY), tiotropium (TRINITY), and indacaterol/glycopyrronium (IND/GLY; TRIBUTE). All studies recruited patients with symptomatic $\mathrm{COPD}, \mathrm{FEV}_{1}<50 \%$, and an exacerbation history. We measured the time to first CID and to sustained CID, an endpoint combining FEV ${ }_{1}$, St George's Respiratory Questionnaire (SGRQ), moderate-to-severe exacerbations, and death. The time to first CID was based on the first occurrence of any of the following: a decrease of $\geq 100 \mathrm{~mL}$ from baseline in $\mathrm{FEV}_{1}$, an increase of $\geq 4$ units from baseline in SGRQ total score, the occurrence of a moderate/severe COPD exacerbation, or death. The time to sustained CID was defined as: a CID in $\mathrm{FEV}_{1}$ and/or SGRQ total score maintained at all subsequent visits, an exacerbation, or death.

Results: Extrafine BDP/FF/G significantly extended the time to first CID vs BDP/FF (HR 0.61, $P<0.001)$, tiotropium $(0.72, P<0.001)$, and IND/GLY $(0.82, P<0.001)$, and significantly extended the time to sustained CID vs BDP/FF (HR 0.64, $P<0.001)$ and tiotropium $(0.80$, $P<0.001$ ), with a numerical extension vs IND/GLY.

Conclusion: In patients with symptomatic $\mathrm{COPD}, \mathrm{FEV}_{1}<50 \%$, and an exacerbation history, extrafine BDP/FF/G delayed disease deterioration compared with BDP/FF, tiotropium, and IND/GLY.

Trial registration: The studies are registered in ClinicalTrials.gov: TRILOGY, NCT01917331; TRINITY, NCT01911364; TRIBUTE, NCT02579850.

Keywords: anticholinergics, beta-2 agonists, chronic obstructive pulmonary disease, disease activity, inhaled corticosteroids

\section{Introduction}

Current pharmacological therapies have been shown to improve quality of life and symptoms and reduce exacerbations in patients with COPD. However, given the progressive nature of COPD, it is important to understand whether a therapy is able to delay clinical deterioration - both in terms of short-term and sustained worsening. Since the clinical manifestation of COPD is multifaceted and impacts different clinical domains, the concept of "clinically important deterioration" (CID) was 
developed, combining a number of clinical parameters, which can measure both short-term and sustained worsening. CID (although with differing definitions) has been used to evaluate the efficacy of a number of long-acting $\beta_{2}$-agonist/long-acting muscarinic antagonist (LABA/LAMA) combinations vs long-acting bronchodilator monotherapy or inhaled corticosteroid (ICS)/LABA combinations, ${ }^{1-6}$ in analyses published as congress abstracts, CID has also been used to compare a LAMA with placebo, ${ }^{7}$ and triple ICS/LAMA/LABA therapy with ICS/LABA.$^{8}$ The advantage of a CID endpoint is that it evaluates deterioration at an individual level, using the same principle as the frequently used responder analyses ${ }^{9,10}$ but capturing health changes in the opposite direction (ie, worsening). Importantly, the occurrence of a CID within the first 6-12 months of the start of a 3-year follow-up period is consistently associated with an increased long-term risk of exacerbations and all-cause mortality, and also predicts sustained meaningful loss in $\mathrm{FEV}_{1}$ and health status amongst survivors. ${ }^{11}$

A single triple-combination inhaler containing an extrafine formulation of the ICS beclometasone dipropionate (BDP), the LABA formoterol fumarate (FF), and the LAMA glycopyrronium $(\mathrm{G})$ has been developed to simplify therapy in patients with COPD, whilst ensuring efficient lung delivery of all three molecules. Three large, 1-year studies have evaluated the efficacy and safety of this triple combination. In TRILOGY, BDP/FF/G provided superior bronchodilation to $\mathrm{BDP} / \mathrm{FF}$, a $23 \%$ reduction in the rate of moderate-tosevere exacerbations, and significant improvements in health status (St George's Respiratory Questionnaire [SGRQ]). ${ }^{12}$ In TRINITY, BDP/FF/G provided superior bronchodilation to tiotropium, a $20 \%$ reduction in the rate of moderate-tosevere exacerbations, and significant improvements in health status. ${ }^{13}$ Finally, in TRIBUTE BDP/FF/G reduced the rate of moderate-to-severe exacerbations by $15 \%$ compared with the fixed-dose combination of indacaterol and glycopyrronium (IND/GLY). ${ }^{14}$ In the current manuscript, we use CID to further evaluate the efficacy of BDP/FF/G, using data from TRILOGY, TRINITY, and TRIBUTE.

\section{Methods}

\section{Trial design}

The designs and results of the pre-specified analyses of TRILOGY, TRINITY, and TRIBUTE have been previously published. ${ }^{12-14}$ All three studies were randomized, parallelgroup, double-blind, and 12 months in duration. The most substantial difference between the studies was the medication administered during the 2-week run-in period: in TRILOGY, all patients received $\mathrm{BDP} / \mathrm{FF}$; in TRINITY, all patients received tiotropium; in TRIBUTE, all patients received IND/GLY. Of note, no patients had their treatment stepped down at the end of run-in.

After run-in, all three studies randomized one group of patients to receive extrafine $\mathrm{BDP} / \mathrm{FF} / \mathrm{G} 87 / 5 / 9 \mu \mathrm{g}$ (corresponding to a nominal dose of $100 / 6 / 10 \mu \mathrm{g}$ ) two puffs twice daily (BID) via pressurized metered dose inhaler (pMDI). The comparator groups were: TRILOGY, extrafine BDP/FF 87/5 $\mu \mathrm{g}$ (nominal dose 100/6 $\mu \mathrm{g}$ ), two puffs BID via pMDI; TRINITY, tiotropium $18 \mu \mathrm{g}$ once daily (OD) via single-dose dry-powder inhaler (SDDPI), or extrafine BDP/FF $87 / 5 \mu \mathrm{g}$ two puffs BID via pMDI plus tiotropium $18 \mu \mathrm{g}$ OD via SDDPI; TRIBUTE, IND/GLY 85/43 $\mu \mathrm{g}$ one puff OD via SDDPI.

In all three studies, $\mathrm{FEV}_{1}$ and SGRQ were assessed at baseline and at Weeks 4, 12, 26, 40, and 52. The occurrence of moderate-to-severe exacerbations was assessed over the duration of the studies, with moderate exacerbations being those resulting in treatment with systemic corticosteroids and/or antibiotics, and severe exacerbations resulting in hospital admission or death. In TRILOGY only, dyspnea was assessed using the Baseline and Transition Dyspnea Index (BDI/TDI), at the same visits as for FEV ${ }_{1}$ and SGRQ. All patients provided written informed consent prior to any study-related procedure. The studies were approved by the independent ethics committees or research boards at each institution, and were performed in accordance with the principles of the Declaration of Helsinki and the International Conference on Harmonization notes for guidance on Good Clinical Practice (ICH/CPMP/135/95). See list of Ethics Committees. The studies are registered in ClinicalTrials. gov: TRILOGY, NCT01917331; TRINITY, NCT01911364; TRIBUTE, NCT02579850.

\section{Participants}

All three studies recruited patients with a diagnosis of COPD, post-bronchodilator $\mathrm{FEV}_{1}<50 \%$ predicted, and a ratio of $\mathrm{FEV}_{1} / \mathrm{FVC}<0.7$, at least one moderate or severe COPD exacerbation in the previous 12 months, and a COPD Assessment Test total score $\geq 10$. TRILOGY also required all patients to have a BDI focal score $\leq 10$ at screening, confirmed at the randomization visit. Full inclusion and exclusion criteria are listed in the primary publications. ${ }^{12-14}$

\section{Outcomes}

This manuscript focuses on two main types of CID analyses: time to first CID and time to sustained CID. Time to first CID was based on the first occurrence of any of the following:

- decrease $\geq 100 \mathrm{~mL}$ from baseline in $\mathrm{FEV}_{1}$;

- increase $\geq 4$ units from baseline in SGRQ total score; 
- occurrence of a moderate/severe COPD exacerbation;

- death.

An additional analysis was performed for TRILOGY that also included a TDI focal score $\leq-1$ unit. Time to sustained CID used the above endpoints, and was defined as: ${ }^{4}$

- a CID in $\mathrm{FEV}_{1}$ and/or SGRQ total score maintained at all subsequent visits (and/or TDI focal score in the additional TRILOGY analysis);

- an exacerbation; or

- death.

An alternative sustained CID definition was used in which an exacerbation was only considered to be a sustained CID if it was accompanied by a CID in $\mathrm{FEV}_{1}$ and/or SGRQ at all subsequent visits (and/or TDI focal score in the additional TRILOGY analysis), or study discontinuation due to the event, or at least one further exacerbation.

\section{Statistical methods}

Analyses were performed on the intention-to-treat populations, defined as all randomized patients who received at least one dose of study drug and had at least one post-baseline efficacy assessment. The times to first and to sustained CID were compared between groups using Cox proportional hazards model including effects for treatment, country, number of COPD exacerbations in the previous year, severity of airflow limitation (post-bronchodilator $\mathrm{FEV}_{1}<30 \%$ predicted, or $30 \%$ to $<50 \%$ predicted) and smoking status at screening. Data are presented as Kaplan-Meier curves, together with HRs and 95\% CIs. The proportion of patients with overall CID and sustained CID and each component of the CID and sustained CID were also calculated.

\section{Results}

\section{Participants}

The baseline demographics and disease characteristics of the patients included in these analyses are shown in Table 1. With the exception of SGRQ total score, there were no substantial differences between groups, either within or between the three studies. In both treatment groups in TRIBUTE, the mean SGRQ total score was lower (ie, better) than in either TRILOGY or TRINITY.

\section{Outcomes}

\section{TRILOGY - without TDI}

As shown in Figure 1A, using the definition that did not include TDI, BDP/FF/G significantly extended the time to first CID compared with BDP/FF (HR 0.61, $P<0.001$ ). BDP/ FF/G also significantly extended the time to sustained CID compared with BDP/FF (HR 0.64, $P<0.001$; Figure 1B). Similar results were seen in the alternative sustained CID

Table I Baseline characteristics (intention-to-treat population)

\begin{tabular}{|c|c|c|c|c|c|c|c|}
\hline \multirow[t]{2}{*}{ Characteristics } & \multicolumn{2}{|l|}{ TRILOGY } & \multicolumn{3}{|l|}{ TRINITY } & \multicolumn{2}{|l|}{ TRIBUTE } \\
\hline & $\begin{array}{l}\text { BDP/FF/G } \\
(\mathbf{N}=687)\end{array}$ & $\begin{array}{l}\text { BDP/FF } \\
(\mathbf{N}=680)\end{array}$ & $\begin{array}{l}\text { BDP/FF/G } \\
(\mathbf{N}=1,077)\end{array}$ & $\begin{array}{l}\text { Tiotropium } \\
(\mathbf{N}=1,074)\end{array}$ & $\begin{array}{l}\text { BDP/FF + } \\
\text { tiotropium } \\
(\mathbf{N}=538)\end{array}$ & $\begin{array}{l}\text { BDP/FF/G } \\
(\mathbf{N}=764)\end{array}$ & $\begin{array}{l}\text { IND/GLY } \\
(\mathbf{N}=\mathbf{7 6 8})\end{array}$ \\
\hline \multicolumn{8}{|l|}{ Gender } \\
\hline Male & 509 (74.1\%) & 527 (77.5\%) & 829 (77.0\%) & 829 (77.2\%) & 398 (74.0\%) & 548 (7I.7\%) & 552 (7I.9\%) \\
\hline \multicolumn{8}{|l|}{ Race } \\
\hline White & $684(99.6 \%)$ & 679 (99.9\%) & I,067 (99.1\%) & I,069 (99.5\%) & 533 (99.1\%) & 705 (92.3\%) & 708 (92.2\%) \\
\hline Other & $3(0.4 \%)$ & I (0.1\%) & $10(0.9 \%)$ & $5(0.5 \%)$ & $5(0.9 \%)$ & $5 \mathrm{I}(6.7 \%)$ & $52(6.8 \%)$ \\
\hline Missing ${ }^{\mathrm{a}}$ & 0 & 0 & 0 & 0 & 0 & $8(1.0)$ & $8(1.0)$ \\
\hline Age (years) & $63.3(7.9)$ & $63.8(8.2)$ & $63.4(8.7)$ & $63.3(8.4)$ & $62.6(8.9)$ & $64.4(7.7)$ & $64.5(7.7)$ \\
\hline \multicolumn{8}{|l|}{ Smoking status } \\
\hline Ex-smoker & 364 (53.0\%) & 362 (53.2\%) & $560(52.0 \%)$ & 573 (53.4\%) & $27 \mathrm{I}(50.4 \%)$ & $4 \mid 3(54.1 \%)$ & 436 (56.8\%) \\
\hline Current smoker & $323(47.0 \%)$ & 318 (46.8\%) & $517(48.0 \%)$ & $50 \mathrm{I}(46.6 \%)$ & 267 (49.6\%) & $35 I(45.9 \%)$ & 332 (43.2\%) \\
\hline $\mathrm{FEV}_{1} \%$ predicted $^{\mathrm{b}}$ & $36.9(8.4)$ & $36.2(8.6)$ & $36.6(8.3)$ & $36.6(8.2)$ & $36.7(8.3)$ & $36.4(8.0)$ & $36.4(8.1)$ \\
\hline$\geq 30 \%$ & 532 (77.4\%) & $525(77.2 \%)$ & 849 (78.8\%) & 845 (78.7\%) & 425 (79.0\%) & $610(79.8 \%)$ & 608 (79.2\%) \\
\hline$<30 \%$ & 155 (22.6\%) & 155 (22.8\%) & $228(21.2 \%)$ & $229(21.3 \%)$ & II3 (2I.0\%) & I 54 (20.2\%) & $160(20.8 \%)$ \\
\hline $\mathrm{FEV}_{\mathrm{l}} / \mathrm{FVC}$ ratio $^{\mathrm{b}}$ & $0.42(0.11)$ & $0.4 I(0 . I I)$ & $0.42(0.10)$ & $0.43(0.11)$ & $0.42(0.10)$ & $0.41(0.10)$ & $0.42(0.10)$ \\
\hline $\begin{array}{l}\text { Exacerbation rate in the } \\
\text { previous year, mean (range) }\end{array}$ & $\mathrm{I} .2(\mathrm{I}, 5)$ & $1.2(I, 6)$ & $I .3(I, I I)$ & $\mathrm{I} .3(\mathrm{I}, 5)$ & I.2(I, 7) & $1.2(I, 6)$ & $1.2(1,4)$ \\
\hline CAT total score & $20.8(5.9)$ & $20.8(5.7)$ & $21.5(5.8)$ & $21.6(5.8)$ & $21.7(6.0)$ & $21.1(5.7)$ & $21.3(5.5)$ \\
\hline SGRQ total score ${ }^{c}$ & $52.3(16.8)$ & $50.3(16.5)$ & $54.4(16.6)$ & $54.5(16.8)$ & $53.0(16.3)$ & $47.6(14.3)$ & $47.7(15.1)$ \\
\hline BDI focal score ${ }^{c}$ & $5.3(1.8)$ & $5.5(1.8)$ & - & - & - & - & - \\
\hline
\end{tabular}

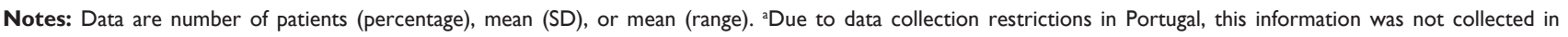
Portuguese sites; 'Post-salbutamol; 'At randomisation visit.

Abbreviations: BDP, beclometasone dipropionate; FF, formoterol fumarate; G, glycopyrronium; IND/GLY, indacaterol/glycopyrronium; CAT, COPD Assessment Test; SGRQ, St George's Respiratory Questionnaire; BDI, Baseline Dyspnea Index. 

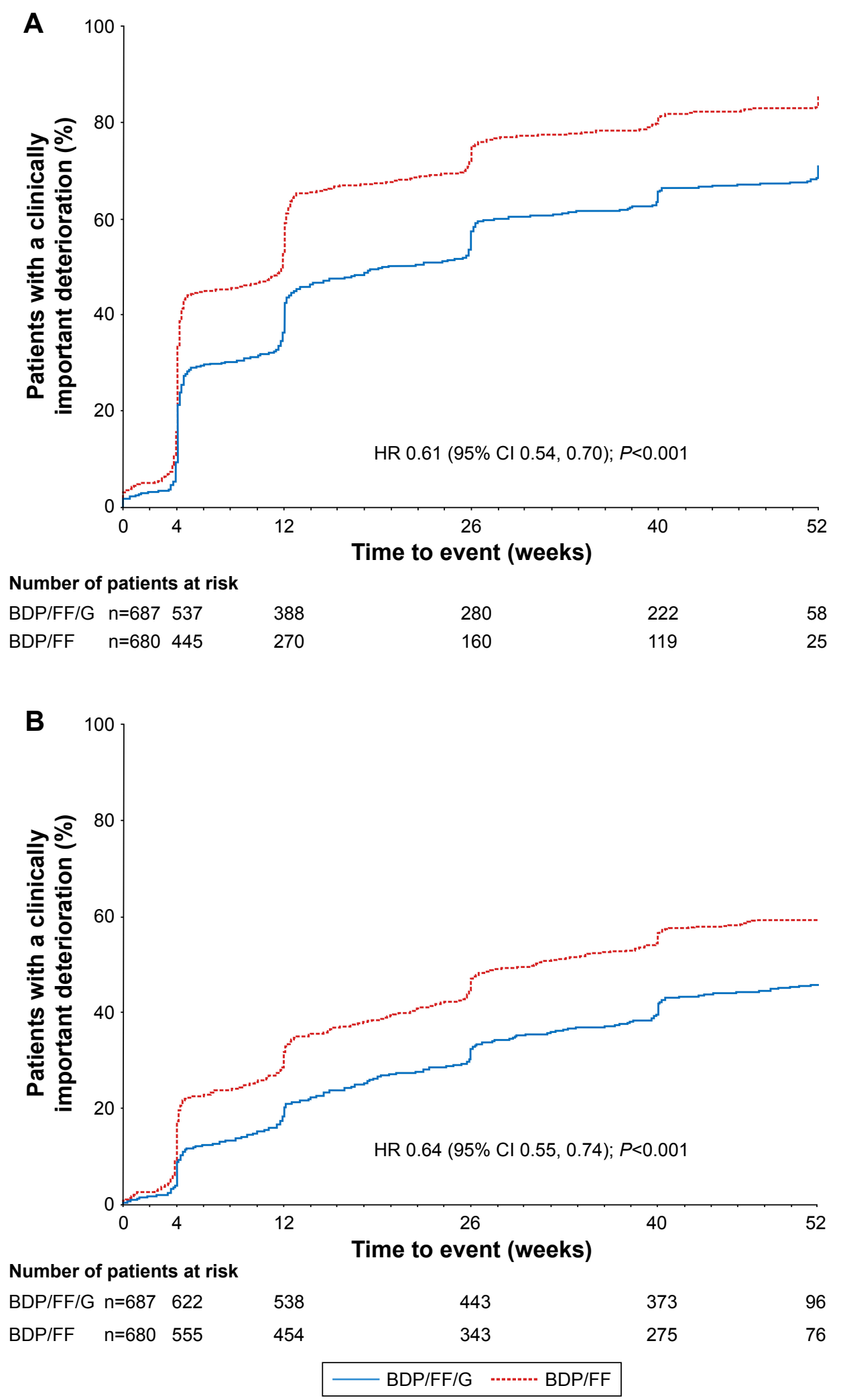

Figure I TRILOGY: Time to (A) first CID and (B) sustained CID (without TDI).

Notes: Time to first CID was based on the first occurrence of any of the following: decrease of $\geq 100 \mathrm{~mL}$ from baseline in FEV; increase of $\geq 4$ units from baseline in SGRQ total score; occurrence of a moderate/severe exacerbation; or death. Time to sustained CID was defined as: a CID in FEV, and/or SGRQ total score maintained at all subsequent visits, occurrence of a moderate/severe exacerbation, or death.

Abbreviations: CID, clinically important deterioration; BDP, beclometasone dipropionate; FF, formoterol fumarate; G, glycopyrronium; TDI, Transition Dyspnea Index; SGRQ, St George's Respiratory Questionnaire. 
definition (HR 0.56, $P<0.001$; Figure S1). A total of $69.9 \%$ of patients in the $\mathrm{BDP} / \mathrm{FF} / \mathrm{G}$ group experienced at least one of the CID components, compared to $83.7 \%$ with BDP/FF (Table 2). All of the individual components contributed to the effect of BDP/FF/G (although the difference in the death component was only numerical, given the small number of events). Sustained CID events were experienced by $44.4 \%$ and $58.1 \%$ of patients in the BDP/FF/G and BDP/FF groups, respectively, using the main definition, and by $29.7 \%$ and $45.4 \%$ with the alternative definition, with all individual components contributing to the results (Table S1).

\section{TRILOGY - with TDI}

The inclusion of TDI in the CID definition increased the occurrence of a CID in both groups (Figure 2A and Table 2). The separation between groups was maintained, with a significant extension in time to first CID with $\mathrm{BDP} / \mathrm{FF} / \mathrm{G}$ (HR 0.62, $P<0.001$ ). Importantly, the time to first deterioration in TDI was significantly extended with $\mathrm{BDP} / \mathrm{FF} / \mathrm{G}$ vs BDP/FF (Table 2). The effect of BDP/FF/G on time to sustained CID was maintained when TDI was included in the definition, with a significant extension compared with $\mathrm{BDP} / \mathrm{FF}$, both with the main definition (HR 0.65, $P<0.001$; Figure 2B) and the alternative definition (HR 0.58, $P<0.001$; Figure S2), with all individual components contributing to the results (Table $\mathrm{S} 1$ ).

\section{TRINITY}

Compared with tiotropium alone, $\mathrm{BDP} / \mathrm{FF} / \mathrm{G}$ significantly extended the time to first CID (HR 0.72, $P<0.001$; Figure $3 \mathrm{~A}$ ), and the time to sustained CID (main definition: HR 0.80, $P<0.001$; Figure 3B; alternative definition: HR 0.72, $P<0.001$; Figure S3). Fewer patients experienced a CID with $\mathrm{BDP} / \mathrm{FF} / \mathrm{G}$ than tiotropium $(74.3 \%$ vs $82.2 \%)$, with all components contributing to the effect, although as with TRILOGY the small number of deaths resulted in only a numerical improvement (Table 2). The two triple therapies had a similar effect. Sustained CID events were experienced by $49.4 \%, 54.4 \%$, and $47.6 \%$ of patients in the $\mathrm{BDP} / \mathrm{FF} / \mathrm{G}$, tiotropium, and $\mathrm{BDP} / \mathrm{FF}$ + tiotropium groups, respectively, using the main definition, and $32.8 \%, 41.0 \%$, and $34.0 \%$ with the alternative definition, with all individual components again contributing to the results (Table S1).

\section{TRIBUTE}

$\mathrm{BDP} / \mathrm{FF} / \mathrm{G}$ significantly extended the time to first CID compared with IND/GLY (HR 0.82, $P<0.001$; Figure 4A). Although there was a numerical extension in the time to sustained $\mathrm{CID}$ with $\mathrm{BDP} / \mathrm{FF} / \mathrm{G}$ compared with IND/ GLY, this did not reach significance either in the main (HR 0.90, $P=0.107$; Figure 4B) or the alternative definition (HR 0.86, $P=0.051$; Figure S4). Fewer patients experienced a CID with BDP/FF/G than IND/GLY (81.5\% vs $87.0 \%)$ (Table 2 ). Although all components contributed numerically to this effect, the only difference to reach statistical significance was SGRQ total score. Similarly, for sustained CID, numerically fewer patients experienced an event with BDP/ $\mathrm{FF} / \mathrm{G}$ than IND/GLY for both definitions (57.2\% vs $59.5 \%$ for the main definition and $44.5 \%$ vs $48.2 \%$ for the alternative definition), and although all components contributed to the results, only SGRQ reached statistical significance (Table S1).

Given that all patients in TRIBUTE were receiving a LABA and a LAMA, we used a second CID definition that excluded $\mathrm{FEV}_{1}$. Using this definition, the time to first CID was significantly extended by BDP/FF/G (HR 0.79 [95\% CI $0.70,0.89], P<0.001)$, as was the time to sustained CID (main definition: $0.83[0.71,0.96], P=0.013$; alternative definition: $0.72[0.59,0.87] ; P<0.001)$. A total of $63.0 \%$ patients in the BDP/FF/G group had a CID, compared with $69.8 \%$ in the IND/GLY group, with a sustained CID experienced by $42.0 \%$ vs $47.1 \%$ using the main definition and $24.4 \%$ vs $31.5 \%$ using the alternative definition.

\section{Discussion}

In this post-hoc analysis of data from three large 1-year studies, single-inhaler triple therapy with $\mathrm{BDP} / \mathrm{FF} / \mathrm{G}$ delayed COPD deterioration compared with ICS/LABA and LAMA monotherapy, both for time to first CID and time to sustained CID, and delayed the time to first CID compared with LABA/ LAMA. There was also a benefit of BDP/FF/G on the absolute number of CID and sustained CID events compared to other treatments.

Unlike most COPD clinical trial endpoints, which evaluate differences between treatments based on group mean efficacy, CID assesses disease worsening at an individual patient level. This is potentially informative in a progressive disease such as COPD, as it describes the impact of therapy on the natural history of the disease. Our principal definition of CID (and the selected thresholds) is consistent with that used in other such analyses. ${ }^{1-5,7,8}$ Unlike most of these, we also included death as one of the CID components. We re-ran the analyses excluding death from the definition of CID or sustained CID. Given that few deaths occurred in any of the studies, this had no meaningful impact on the results (data not shown). Despite this, we believe that death is an important 


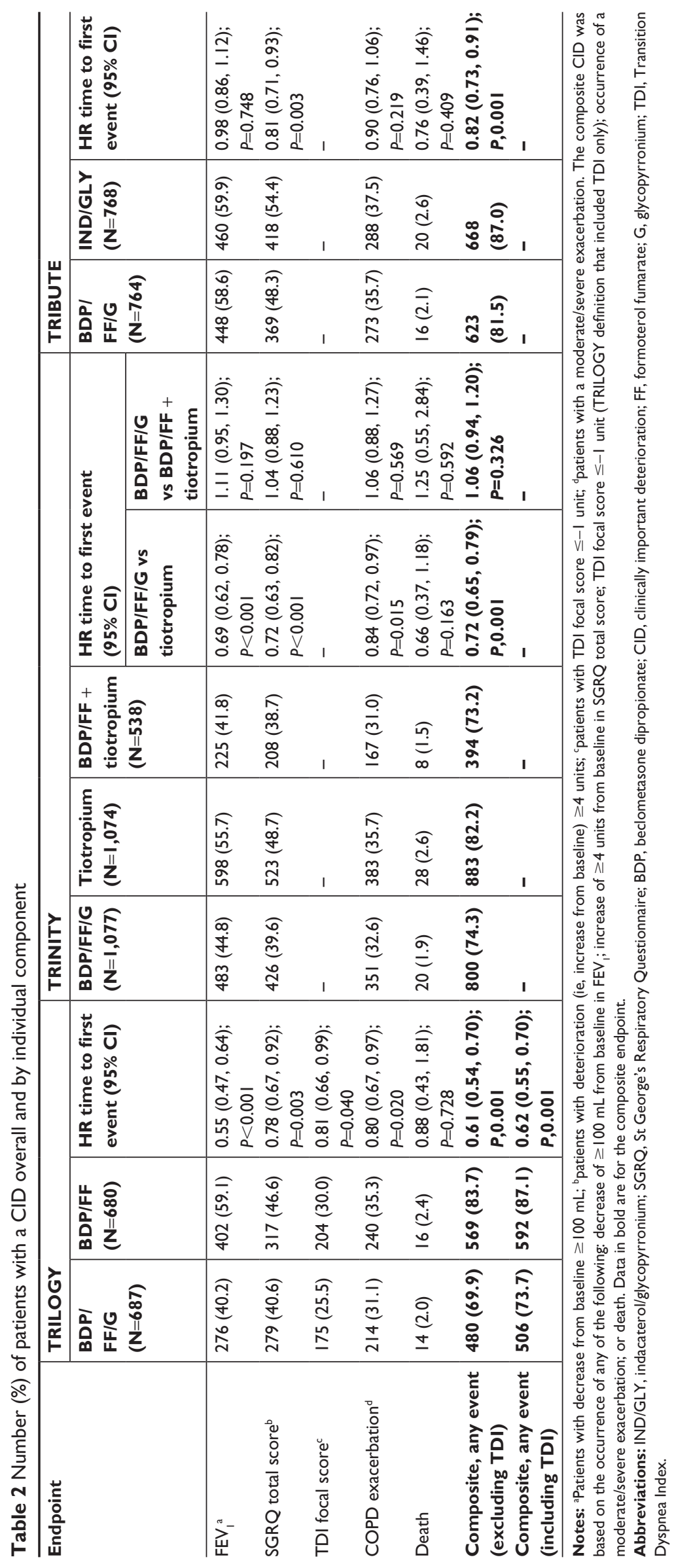



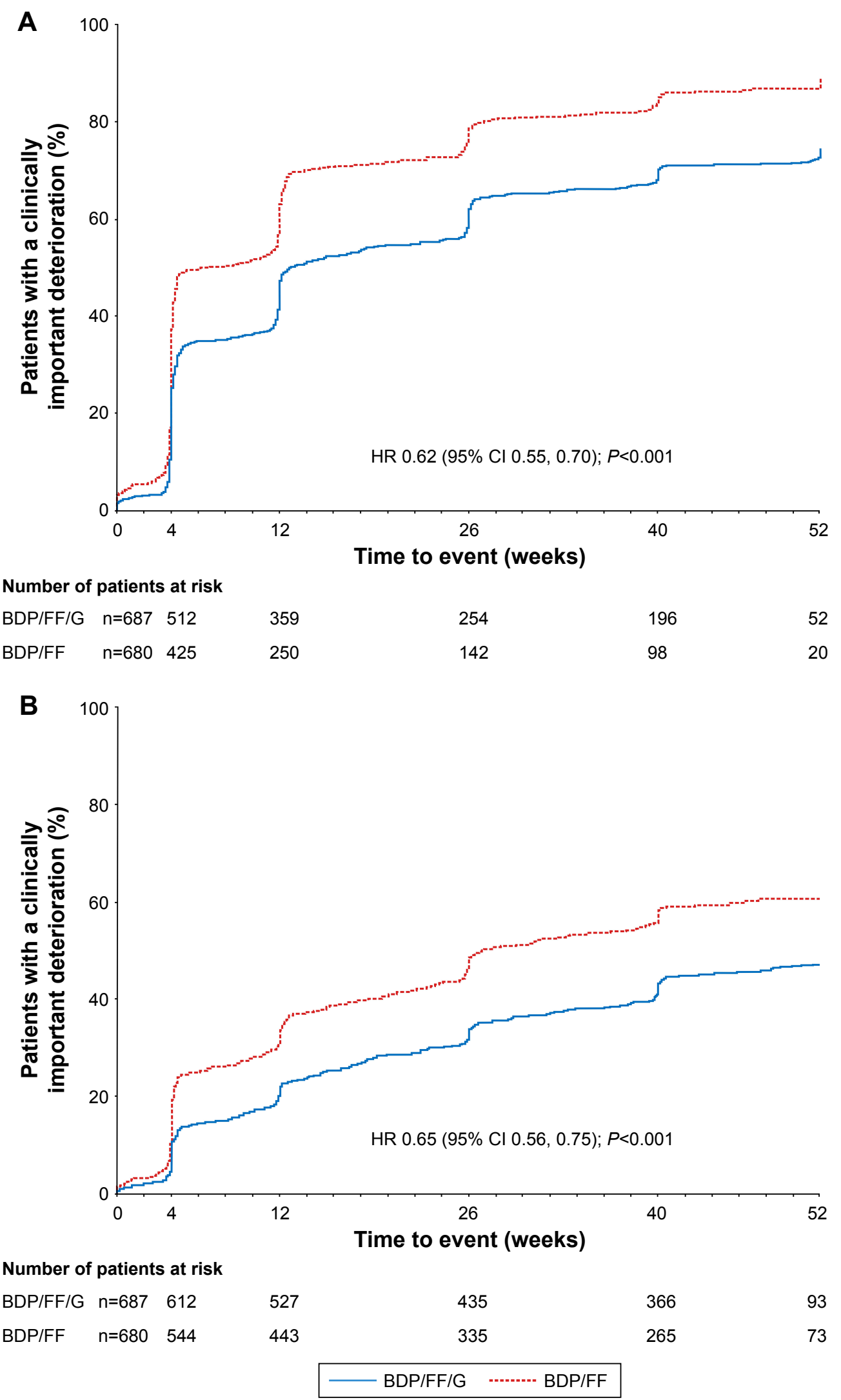

Figure 2 TRILOGY: Time to (A) first CID and (B) sustained CID (with TDI).

Notes: Time to first CID was based on the first occurrence of any of the following: decrease of $\geq 100 \mathrm{~mL}$ from baseline in FEV; increase of $\geq 4$ units from baseline in SGRQ total score; TDI focal score $\leq-I$ unit; occurrence of a moderate/severe exacerbation; or death. Time to sustained CID was defined as: a CID in FEV , and/or SGRQ total score and/or TDI focal score maintained at all subsequent visits, occurrence of a moderate/severe exacerbation, or death.

Abbreviations: CID, clinically important deterioration; BDP, beclometasone dipropionate; FF, formoterol fumarate; G, glycopyrronium; TDI, Transition Dyspnea Index; SGRQ, St George's Respiratory Questionnaire. 


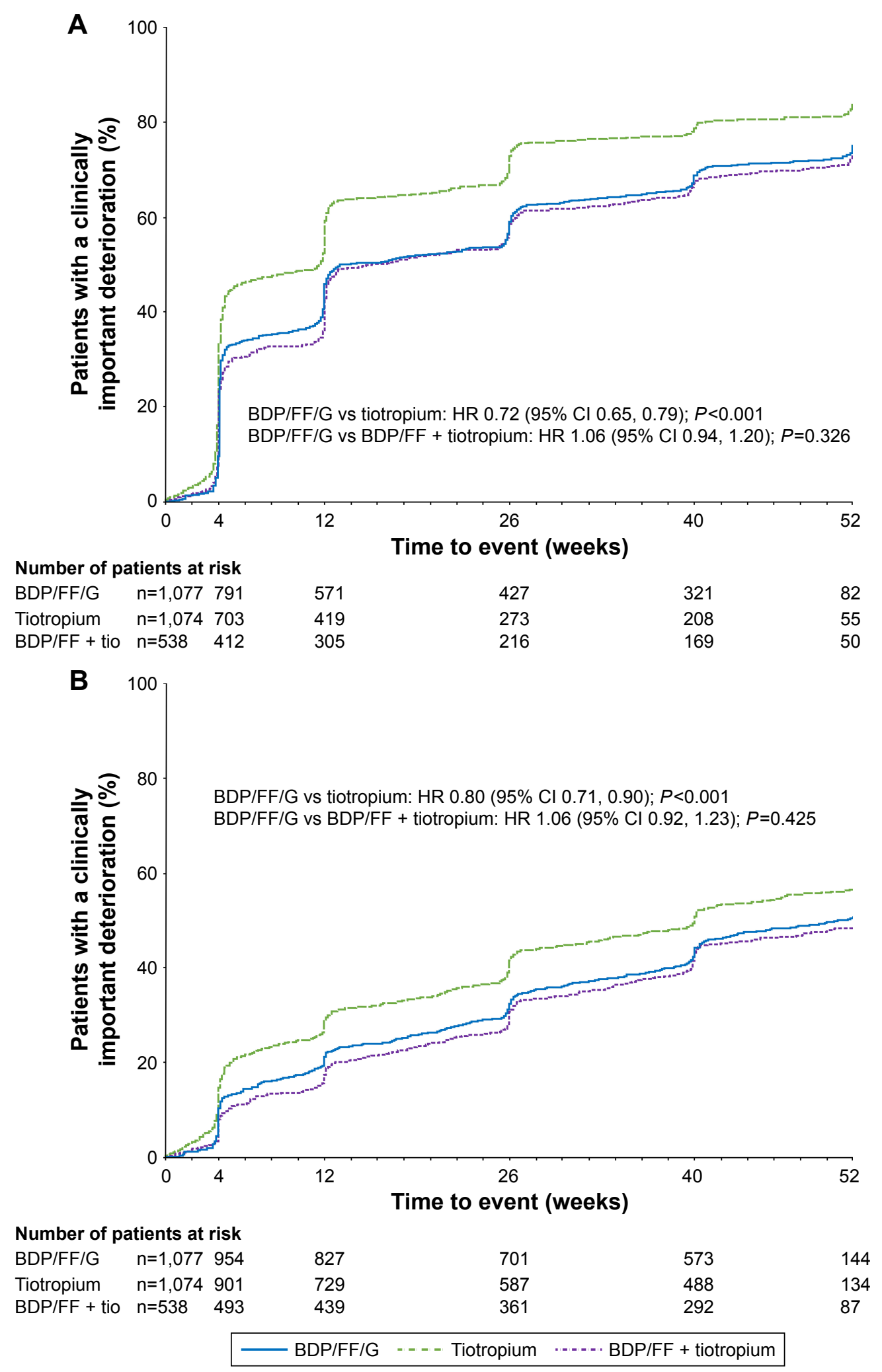

Figure 3 TRINITY: Time to (A) first CID and (B) sustained CID.

Notes: Time to first CID was based on the first occurrence of any of the following: decrease of $\geq 100 \mathrm{~mL}$ from baseline in FEV SGRQ total score, occurrence of a moderate/severe exacerbation, or death. Time to sustained CID was defined as: a CID in FEV , and/or SGRQ total score maintained at all subsequent visits, occurrence of a moderate/severe exacerbation, or death.

Abbreviations: CID, clinically important deterioration; BDP, beclometasone dipropionate; FF, formoterol fumarate; G, glycopyrronium; SGRQ, St George's Respiratory Questionnaire. 

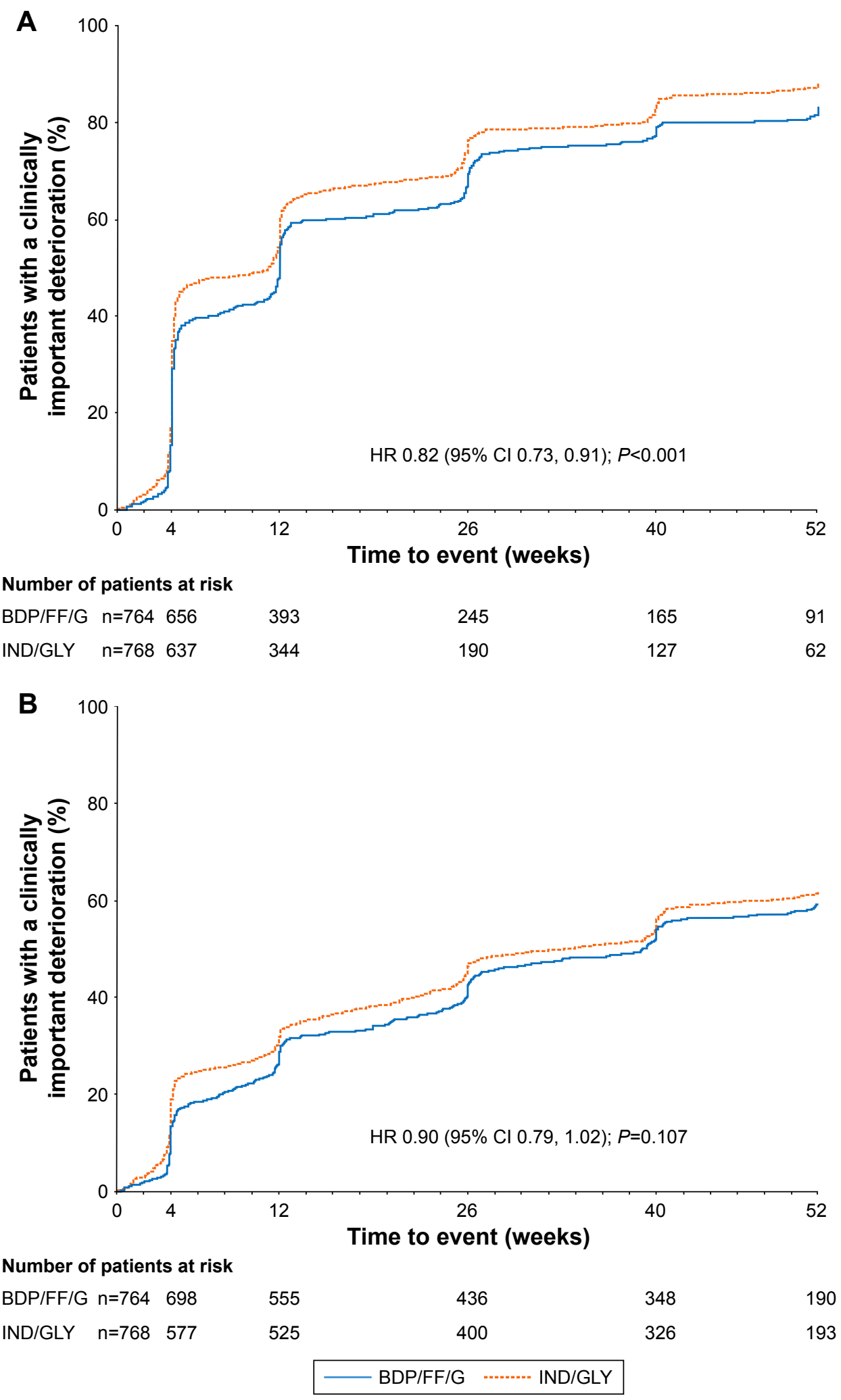

Figure 4 TRIBUTE: Time to (A) first CID and (B) sustained CID.

Notes: Time to first CID was based on the first occurrence of any of the following: decrease of $\geq 100 \mathrm{~mL}$ from baseline in FEV SGRQ total score, occurrence of a moderate/severe exacerbation, or death. Time to sustained CID was defined as: a CID in FEV, and/or SGRQ total score maintained at all subsequent visits, occurrence of a moderate/severe exacerbation, or death.

Abbreviations: CID, clinically important deterioration; BDP, beclometasone dipropionate; FF, formoterol fumarate; G, glycopyrronium; IND/GLY, indacaterol/ glycopyrronium; SGRQ, St George's Respiratory Questionnaire. 
outcome to include in the definition of CID for all long-term (1 year and over) studies in COPD.

CID results should be mainly interpreted as a combined measure (ie, a composite endpoint), but it is also useful to examine the contribution of the individual components. The two parameters that contributed most to clinical deterioration across the three studies were FEV , $_{1}$ and SGRQ. The SGRQ threshold (4 units) was based on a value considered clinically relevant and is used in responder analyses, ${ }^{9}$ while a change from baseline of $100 \mathrm{~mL}_{\text {in }} \mathrm{FEV}_{1}$ has been described as a difference that patients can perceive. ${ }^{15}$ These two aspects of clinical deterioration are likely to impact patients on a dayto-day basis, and so treatments that delay their occurrence are likely to be a valuable treatment option. In addition, although many of the previous CID analyses did not include TDI, the inclusion of this endpoint in the additional analyses for TRILOGY (with a threshold based on the value considered clinically relevant ${ }^{10}$ ) added to the number of events, suggesting that it captures disease information not captured by the other CID components.

Although fewer patients experienced an exacerbation than a deterioration in lung function or health status, a number of studies have shown that exacerbations are associated with faster lung function decline, reduced physical activity levels, and increased mortality risk, and so are key drivers of disease progression. ${ }^{16-26}$ Given the long-term impact of such events, in our main definition a patient with an exacerbation was considered to have experienced a sustained CID (consistent with a definition used previously). ${ }^{4}$ However, there is no single, accepted sustained CID definition. Furthermore, it could be argued that individuals who fully recover from an exacerbation have not suffered a "sustained" deterioration. We therefore also used an alternative definition that required patients who exacerbated to have subsequent evidence of deterioration in other clinical parameters $\left(\mathrm{FEV}_{1}, \mathrm{SGRQ}\right.$, and/or TDI), or withdrew from the study due to the exacerbation, or had a subsequent exacerbation. Fewer patients met this more stringent definition, but the relative treatment effects in these analyses were consistent with those in the main analyses, so confirming the effect of the treatment on sustained CID (irrespective of its definition).

Other CID analyses have pooled data from one or more similar studies. $^{2-4}$ Although TRILOGY, TRINITY, and TRIBUTE had very similar inclusion criteria and almost identical efficacy endpoints, we decided to evaluate CID individually in the three studies. There were two main reasons for this. Firstly, the large size of the three studies meant that the groups were sufficiently large to draw firm conclusions (and were larger than the pooled groups in many other CID analyses). Secondly, we are able to draw conclusions on the relative consistency of the results of these studies. It is therefore informative that the percentage of patients with a CID in the BDP/FF/G group in TRILOGY and TRINITY is very similar $(70 \%$ vs $74 \%)$, as was the percentage with deterioration of each component. The percentage of patients in the BDP/FF/G group with a CID in TRIBUTE was substantially higher ( $82 \%$ ), with $\sim 40 \%$ having a CID by Week 4 , compared with $\sim 30 \%$ in TRILOGY and TRINITY. We speculate two possible explanations for this. Firstly, all patients in TRILOGY and TRINITY received one bronchodilator during the run-in period (FF in TRILOGY and tiotropium in TRINITY), whereas all patients in TRIBUTE received the dual bronchodilator IND/GLY. This means at the time of the baseline assessment, the lung function of patients in TRIBUTE was potentially optimized, making subsequent decline more likely (as indicated by the Week 4 data). Secondly, although the majority of the baseline characteristics were similar across the three studies, patients in TRIBUTE had lower (ie, better) mean SGRQ total scores; this makes a decline in SGRQ score in individual patients more likely in TRIBUTE (although overall there was an improvement in SGRQ mean score in this study). ${ }^{14}$

The main CID analyses used definitions that included $\mathrm{FEV}_{1}$ decline, to ensure that the results were comparable with other published analyses. In TRIBUTE, a narrower CID definition excluding $\mathrm{FEV}_{1}$ resulted in fewer events in both groups, with the time to first CID and the time to sustained CID with BDP/FF/G both significantly extended vs IND/GLY. This suggests that a single CID definition may not be appropriate for all analyses. Further, although a number of analyses have shown a correlation between $\mathrm{FEV}_{1}$ and a range of patient-relevant outcomes (at a group level, at least), ${ }^{27,28}$ $\mathrm{FEV}_{1}$ is not the main target of therapy in daily practice. ${ }^{29}$

The fact that $30 \%-57 \%$ of patients had a sustained CID despite receiving $\mathrm{BDP} / \mathrm{FF} / \mathrm{G}$ may reflect the progressive nature of COPD. This is higher than observed in other studies (eg, 30.4\% receiving aclidinium/formoterol ${ }^{4}$ and $20 \%-24 \%$ receiving umeclidinium/vilanterol). ${ }^{1}$ However, this is indicative of the greater disease severity of patients recruited into TRILOGY, TRINITY, and TRIBUTE, all of whom had at least one exacerbation in the prior 12 months and so had more unstable disease, and the longer duration of follow-up (12 months compared with 24 weeks). Importantly, data from the early termination visits (ie, withdrawal prior to 52 weeks) were included in our analyses (the percentage of patients prematurely discontinuing ranged from $7.8 \%$ to 
$15.6 \%$ across treatment groups in the three studies). ${ }^{12-14}$ This is a strength of our work, since premature study discontinuations are often due to a decline in a patient's condition, and so a visit performed at the time of study withdrawal may be able to capture this deterioration.

Although the similar inclusion criteria of the three studies are a strength, this is also a potential limitation, in that we cannot draw any conclusions on the effect of BDP/FF/G in less severe populations. However, the population recruited into TRILOGY, TRINITY, and TRIBUTE is also consistent with the patients likely to receive $\mathrm{BDP} / \mathrm{FF} / \mathrm{G}$ in day-to-day clinical practice. Another limitation (common with all CID analyses) is that the most common events are those that occur at distinct time points $\left(\mathrm{FEV}_{1}, \mathrm{SGRQ}\right.$, and TDI were only assessed at study visits), so limiting the precision of the HRs. However, this also reflects clinical practice in that a treating physician will evaluate disease progression (or treatment failure) on the basis of assessments conducted at scheduled visits or on major events (ie, exacerbations).

\section{Conclusion}

The analyses presented here complement the pre-specified analyses presented in the primary manuscripts. ${ }^{12-14}$ In this group of patients with severe or very severe airflow limitation and an exacerbation history, extrafine BDP/ $\mathrm{FF} / \mathrm{G}$ delayed disease deterioration compared with BDP/ FF, tiotropium, and IND/GLY. These findings emphasize the important role that triple therapy can play in the management of COPD.

\section{Data availability}

Chiesi commits to sharing with qualified scientific and medical researchers, conducting legitimate research, the anonymized patient-level data, the study-level data, the clinical protocol and the full CSR of Chiesi Farmaceutici SpA-sponsored interventional clinical trials in patients for medicines and indications approved by the European Medicines Agency and/or the US Food and Drug Administration after 1 January 2015.

Chiesi commits to sharing the clinical data of TRILOGY (NCT01917331) and TRINITY (NCT01911364) studies starting from 1 January 2019, following the approval of any received research proposal and the signature of a Data Sharing Agreement. Chiesi provides access to clinical trial information consistently with the principle of safeguarding commercially confidential information and patient privacy. To date, TRIBUTE (NCT02579850) is out of scope of the Chiesi policy on clinical data sharing.
Other information on Chiesi's data sharing commitment, access, and research request's approval process will be available from 1 January 2019 in the Clinical Trial Transparency section of this webpage page: http://www.chiesi.com/en/ research-and-development/.

\section{Acknowledgments}

The authors would like to thank the investigators and patients at the investigative sites for their support of these studies.

Writing support was provided by David Young of Young Medical Communications and Consulting Ltd. This writing support was funded by Chiesi Farmaceutici SpA. TRILOGY, TRINITY, and TRIBUTE were funded by Chiesi Farmaceutici SpA. Employees of Chiesi Farmaceutici were involved in the design and conduct and interpretation of the analyses reported in this article, and (as authors) in the development of the manuscript.

\section{Disclosure}

DS is supported by the National Institute for Health Research (NIHR) Manchester Biomedical Research Centre (BRC). DS received personal fees from Chiesi during the conduct of these studies. Outside the submitted work, DS reports grants and personal fees from Almirall, AstraZeneca, Boehringer Ingelheim, Chiesi, GlaxoSmithKline, Glenmark, Johnson and Johnson, Merck, NAPP, Novartis, Pfizer, Takeda, Teva, Theravance, and Verona, and personal fees from Genentech and Skyepharma. LMF reports grants, personal fees, and non-financial support from Boehringer Ingelheim, Chiesi Farmaceutici, GlaxoSmithKline, Merck Sharp \& Dohme, Takeda, AstraZeneca, Novartis, Menarini, Laboratori Guidotti, and Almirall; personal fees and non-financial support from Pearl Therapeutics, Mundipharma, and Boston Scientific; personal fees from Kyorin, Bayer, and Zambon; and grants from Pfizer, Dompè, Malesci, Alfasigma, and Vree Health Italia, all outside the submitted work. SV and SP are employed by Chiesi, the sponsor of the studies. AP reports grants, personal fees, non-financial support, and advisory board membership from Chiesi, AstraZeneca, GlaxoSmithKline, Boehringer Ingelheim, Mundipharma, and TEVA; personal fees and non-financial support from Menarini, Novartis, and Zambon; and grants from Sanofi, all outside the submitted work. The authors report no other conflicts of interest in this work.

\section{References}

1. Singh D, Maleki-Yazdi MR, Tombs L, Iqbal A, Fahy WA, Naya I. Prevention of clinically important deteriorations in COPD with umeclidinium/ vilanterol. Int J Chron Obstruct Pulmon Dis. 2016;11(1):1413-1424. 
2. Anzueto A, Vogelmeier C, Kostikas K, et al. The effect of indacaterol/ glycopyrronium versus tiotropium or salmeterol/fluticasone on the prevention of clinically important deterioration in COPD. Int J Chron Obstruct Pulmon Dis. 2017;12:1325-1337.

3. Maleki-Yazdi MR, Singh D, Anzueto A, Tombs L, Fahy WA, Naya I. Assessing short-term deterioration in maintenance-naïve patients with COPD receiving umeclidinium/vilanterol and tiotropium: a pooled analysis of three randomized trials. Adv Ther. 2017;33(12):2188-2199.

4. Singh D, D’Urzo AD, Chuecos F, Muñoz A, Garcia Gil E. Reduction in clinically important deterioration in chronic obstructive pulmonary disease with aclidinium/formoterol. Respir Res. 2017;18(1):106.

5. Anzueto AR, Kostikas K, Mezzi K, et al. Indacaterol/glycopyrronium versus salmeterol/fluticasone in the prevention of clinically important deterioration in COPD: results from the FLAME study. Respir Res. 2018;19(1):121.

6. Greulich T, Kostikas K, Gaga M, et al. Indacaterol/glycopyrronium reduces the risk of clinically important deterioration after direct switch from baseline therapies in patients with moderate COPD: a post hoc analysis of the CRYSTAL study. Int J Chron Obstruct Pulmon Dis. 2018;13:1229-1237.

7. Rabe KF, Metzdorf N, Vob F, Hallmann C, Gronke L, Tashkin DP. Benefits of tiotropium versus placebo for delaying clinically significant events in patients with moderate COPD (GOLD 2). Am J Respir Crit Care Med. 2016;193:A6814.

8. Naya I, Barnacle H, Birk R, et al. Clinically important deterioration in advanced COPD patients using single inhaler triple therapy: results from the FULFIL study. Eur Respir J. 2017;50(suppl 61):PA3248.

9. Jones PW. St. George's Respiratory Questionnaire: MCID. COPD. 2005;2(1):75-79.

10. Mahler DA, Witek TJ. The MCID of the Transition Dyspnea Index is a total score of one unit. COPD. 2005;2(1):99-103.

11. Naya IP, Tombs L, Muellerova H, Compton C, Jones PW. Long-term outcomes following first short-term clinically important deterioration in COPD. Respir Res. 2018;19(1):222.

12. Singh D, Papi A, Corradi M, et al. Single inhaler triple therapy versus inhaled corticosteroid plus long-acting $\beta 2$-agonist therapy for chronic obstructive pulmonary disease (trilogy): a double-blind, parallel group, randomised controlled trial. The Lancet. 2016;388(10048):963-973.

13. Vestbo J, Papi A, Corradi M, et al. Single inhaler extrafine triple therapy versus long-acting muscarinic antagonist therapy for chronic obstructive pulmonary disease (TRINITY): a double-blind, parallel group, randomised controlled trial. The Lancet. 2017;389(10082):1919-1929.

14. Papi A, Vestbo J, Fabbri L, et al. Extrafine inhaled triple therapy versus dual bronchodilator therapy in chronic obstructive pulmonary disease (tribute): a double-blind, parallel group, randomised controlled trial. The Lancet. 2018;391(10125):1076-1084.

15. Donohue JF. Minimal clinically important differences in COPD lung function. COPD. 2005;2(1):111-124
16. Grolimund E, Kutz A, Marlowe RJ, et al. Long-term prognosis in COPD exacerbation: role of biomarkers, clinical variables and exacerbation type. COPD. 2015;12(3):295-305.

17. Goossens LMA, Leimer I, Metzdorf N, Becker K, Rutten-van Mölken MPMH. Does the 2013 GOLD classification improve the ability to predict lung function decline, exacerbations and mortality: a post-hoc analysis of the 4-year UPLIFT trial. BMC Pulm Med. 2014;14(4):163.

18. Celli BR, Thomas NE, Anderson JA, et al. Effect of pharmacotherapy on rate of decline of lung function in chronic obstructive pulmonary disease: results from the torch study. Am J Respir Crit Care Med. 2008;178(4): 332-338.

19. Donaldson GC, Seemungal TAR, Bhowmik A, Wedzicha JA. Relationship between exacerbation frequency and lung function decline in chronic obstructive pulmonary disease. Thorax. 2002;57(10):847-852.

20. Halpin D, Decramer M, Celli B, Kesten S, Liu D, Tashkin D. Exacerbation frequency and course of COPD. Int J Chron Obstruct Pulmon Dis. 2012;7:653-661.

21. Vestbo J, Edwards LD, Scanlon PD, et al. Changes in forced expiratory volume in 1 second over time in COPD. N Engl J Med. 2011;365(13): 1184-1192.

22. Bafadhel M, Mckenna S, Terry S, et al. Acute exacerbations of chronic obstructive pulmonary disease: identification of biologic clusters and their biomarkers. Am J Respir Crit Care Med. 2011;184(6):662-671.

23. Pitta F, Troosters T, Probst VS, Spruit MA, Decramer M, Gosselink R. Physical activity and hospitalization for exacerbation of COPD. Chest. 2006;129(3):536-544.

24. Alahmari AD, Patel ARC, Kowlessar BS, et al. Daily activity during stability and exacerbation of chronic obstructive pulmonary disease. BMC Pulm Med. 2014;14:98.

25. Johannesdottir SA, Christiansen CF, Johansen MB, et al. Hospitalization with acute exacerbation of chronic obstructive pulmonary disease and associated health resource utilization: a population-based Danish cohort study. J Med Econ. 2013;16(7):897-906.

26. Blasi F, Cesana G, Conti S, et al. The clinical and economic impact of exacerbations of chronic obstructive pulmonary disease: a cohort of hospitalized patients. PLoS One. 2014;9(6):e101228.

27. Donohue JF, Jones PW, Bartels C, et al. Correlations between FEV1 and patient-reported outcomes: a pooled analysis of 23 clinical trials in patients with chronic obstructive pulmonary disease. Pulm Pharmacol Ther. 2018;49:11-19.

28. Jones PW, Donohue JF, Nedelman J, Pascoe S, Pinault G, Lassen C. Correlating changes in lung function with patient outcomes in chronic obstructive pulmonary disease: a pooled analysis. Respir Res. 2011; $12: 161$.

29. Global Initiative for Chronic Obstructive Lung Disease. Global Strategy for the diagnosis, management, and prevention of chronic obstructive pulmonary disease. Available from: https://goldcopd.org. Published 2019. Accessed December 28, 2018. 


\section{Supplementary materials}

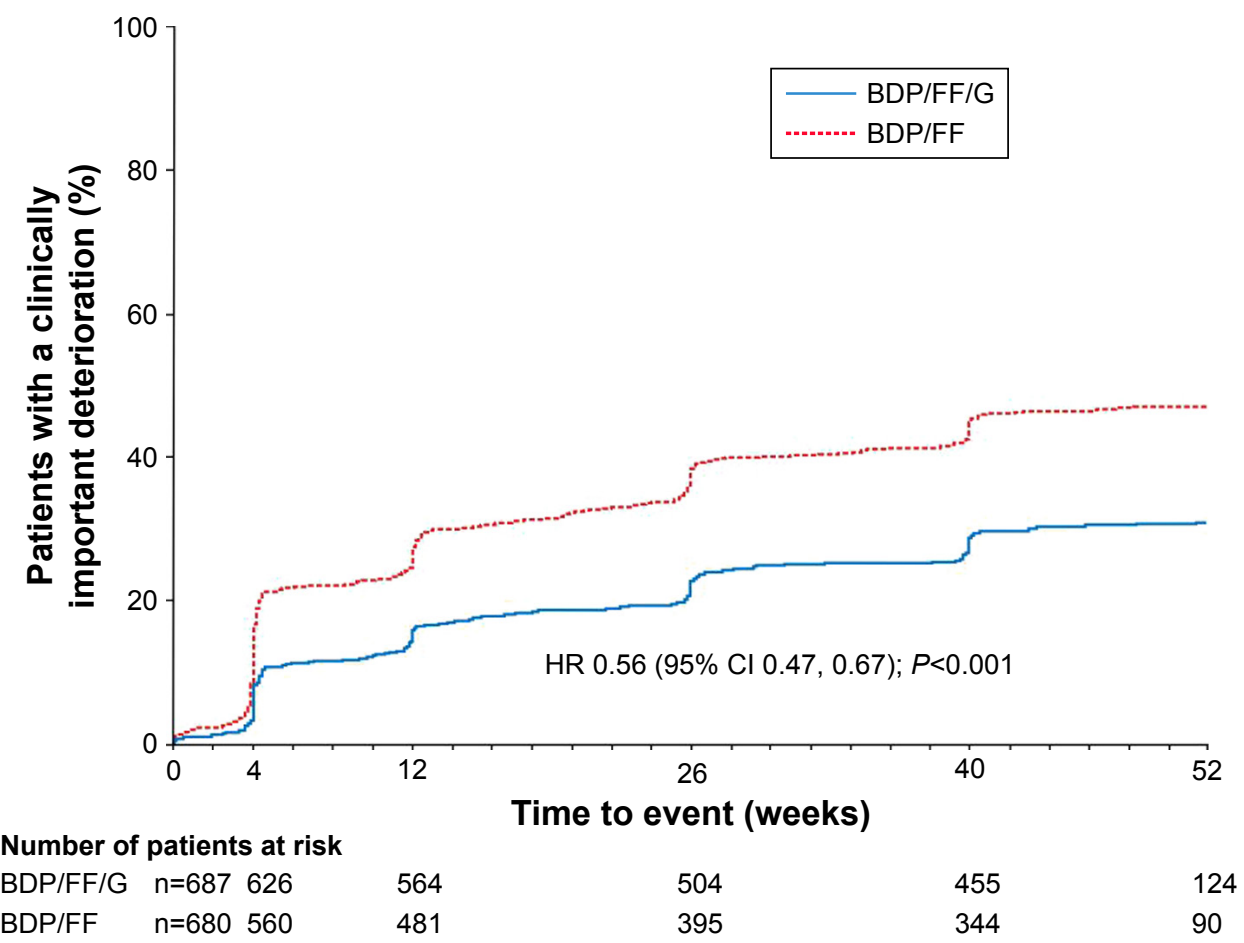

Figure SI TRILOGY: Time to sustained CID (without TDI), alternative definition.

Notes: Time to sustained CID was defined as: a CID in FEV, and/or SGRQ total score maintained at all subsequent visits; a moderate/severe exacerbation followed by a $\mathrm{CID}$ in FEV, and/or SGRQ total score at all subsequent visits, or the exacerbation resulted in study discontinuation, or they had at least one further exacerbation; or death. Abbreviations: CID, clinically important deterioration; BDP, beclometasone dipropionate; FF, formoterol fumarate; G, glycopyrronium; TDI, Transition Dyspnea Index; SGRQ, St George's Respiratory Questionnaire. 


\begin{tabular}{|c|c|c|c|c|c|c|c|c|c|c|c|c|c|c|c|c|c|c|}
\hline \multirow[b]{3}{*}{ 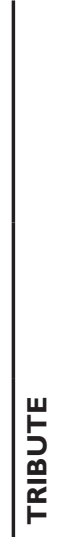 } & \multicolumn{2}{|l|}{ 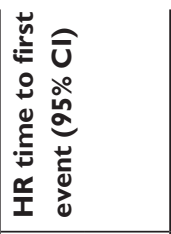 } & \multicolumn{3}{|c|}{ 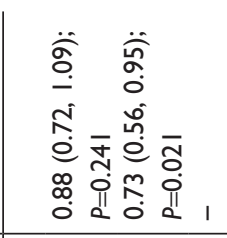 } & \multicolumn{4}{|c|}{ 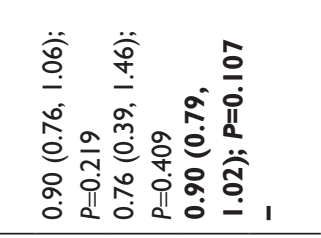 } & \multicolumn{3}{|c|}{ 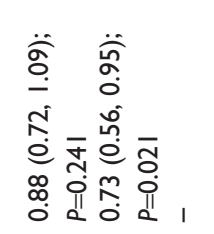 } & \multicolumn{2}{|c|}{ 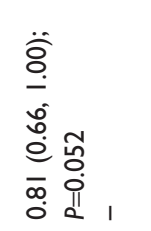 } & \multicolumn{3}{|c|}{ 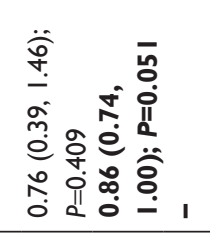 } & \multirow{12}{*}{ 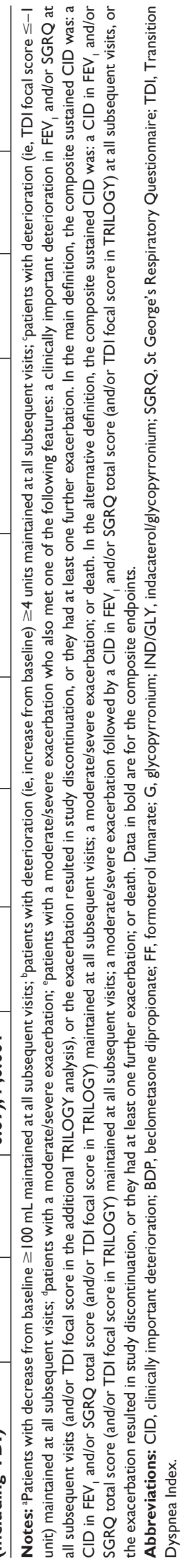 } \\
\hline & 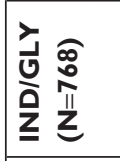 & & 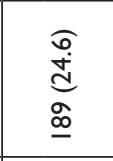 & 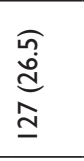 & 1 & 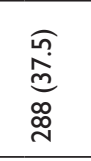 & $\begin{array}{l}0 \\
\text { d } \\
\text { ¿ } \\
\end{array}$ & 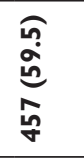 & 1 & 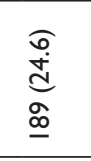 & 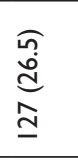 & 1 & $\begin{array}{l}\widehat{o} \\
\stackrel{0}{d} \\
\stackrel{0}{\infty} \\
\underline{0}\end{array}$ & 1 & $\begin{array}{l}\widehat{0} \\
\stackrel{d}{0} \\
\text { i }\end{array}$ & $\underset{8}{+}$ & & \\
\hline & 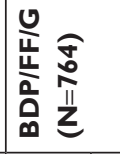 & & $\begin{array}{l}\widetilde{\tilde{d}} \\
\text { ḋ } \\
\stackrel{8}{\underline{\Omega}}\end{array}$ & 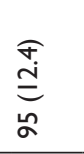 & 1 & 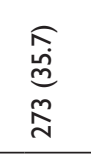 & $\begin{array}{l}\widehat{\bar{d}} \\
\underline{0}\end{array}$ & $\begin{array}{l}\underset{n}{n} \\
\mathfrak{n} \\
\tilde{m} \\
m\end{array}$ & 1 & $\begin{array}{l}\widehat{\widetilde{d}} \\
\stackrel{d}{\Omega} \\
\underline{\underline{\Omega}}\end{array}$ & 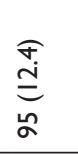 & 1 & $\begin{array}{l}\frac{1}{a} \\
\bar{d} \\
\underline{0} \\
\underline{0}\end{array}$ & 1 & $\begin{array}{l}\widehat{\bar{d}} \\
0 \\
\underline{-}\end{array}$ & 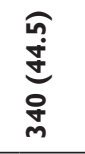 & $\mathrm{I}$ & \\
\hline \multirow{5}{*}{ 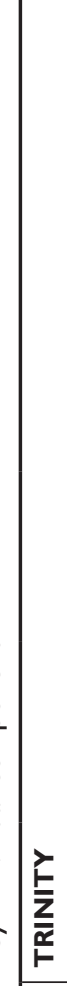 } & \multirow{2}{*}{\multicolumn{2}{|c|}{ 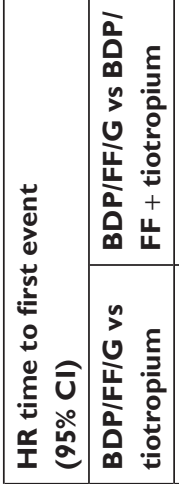 }} & 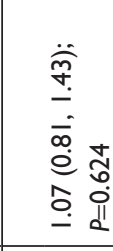 & 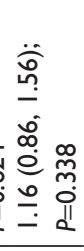 & & 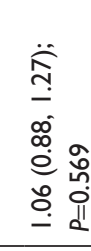 & & 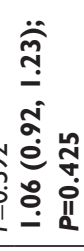 & & 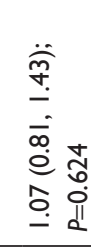 & 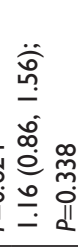 & & \multicolumn{2}{|c|}{ 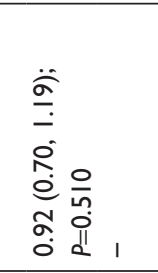 } & \multicolumn{2}{|c|}{ 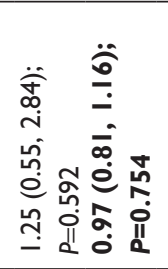 } & & \\
\hline & & & 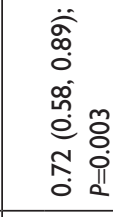 & 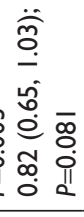 & & 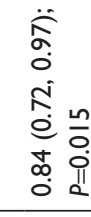 & 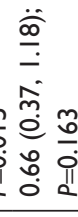 & 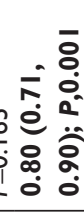 & & 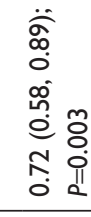 & 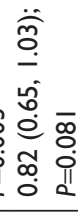 & & 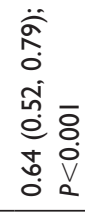 & & 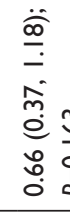 & 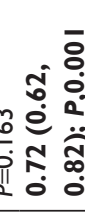 & & \\
\hline & 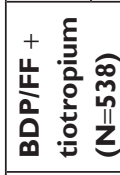 & & $\begin{array}{l}\stackrel{o}{0} \\
\stackrel{m}{ٍ} \\
\stackrel{R}{R}\end{array}$ & 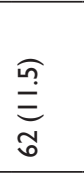 & 1 & $\begin{array}{l}\frac{a}{a} \\
\frac{n}{\hat{0}} \\
\underline{0}\end{array}$ & 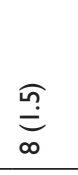 & 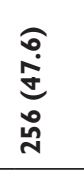 & 1 & 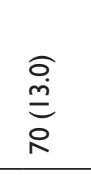 & 命 & 1 & 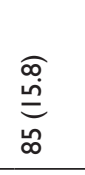 & 1 & $\underset{\infty}{\stackrel{n n}{=}}$ & $\begin{array}{l}\hat{\sigma} \\
\dot{j} \\
\tilde{m} \\
\underline{\infty} \\
\end{array}$ & 1 & \\
\hline & 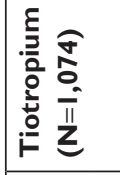 & & 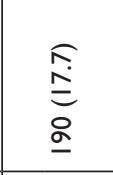 & 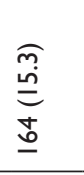 & 1 & 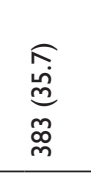 & $\begin{array}{l}\stackrel{\sigma}{d} \\
\stackrel{\infty}{d} \\
\stackrel{\sim}{N}\end{array}$ & 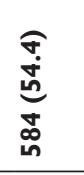 & 1 & 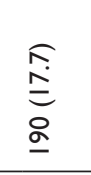 & 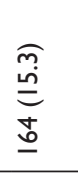 & 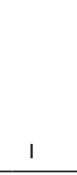 & $\begin{array}{l}\widehat{\bar{i}} \\
\stackrel{i}{a}\end{array}$ & 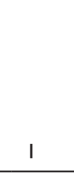 & $\begin{array}{l}\widehat{0} \\
\stackrel{d}{d} \\
\stackrel{\infty}{N} \\
\end{array}$ & 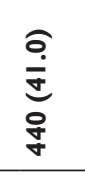 & 1 & \\
\hline & 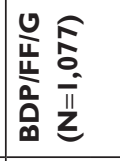 & & 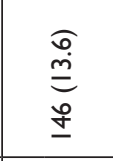 & 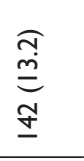 & 1 & 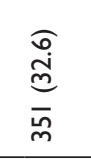 & 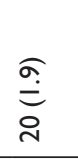 & 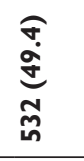 & 1 & 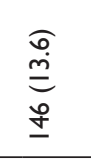 & 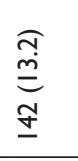 & 1 & 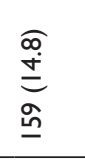 & 1 & 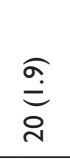 & $\begin{array}{l}\underset{\infty}{0} \\
\stackrel{\tilde{m}}{m} \\
\stackrel{m}{0} \\
m\end{array}$ & 1 & \\
\hline & 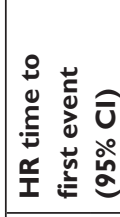 & & 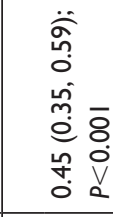 & 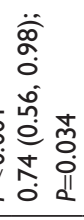 & $\begin{array}{l}\ddot{\hat{j}} \\
0 \\
o \\
o \\
\stackrel{0}{0}\end{array}$ & $\begin{array}{r}\ddot{\bar{\sigma}} \\
\dot{0} \\
\hat{s} \\
\dot{0} 0 \\
0\end{array}$ & 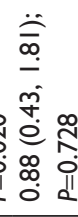 & 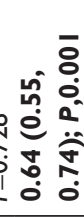 & 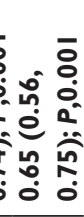 & 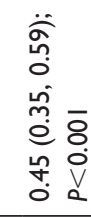 & 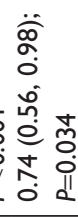 & 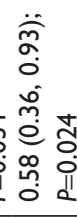 & 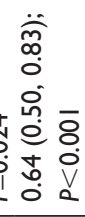 & 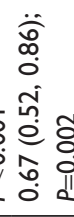 & $\begin{array}{l}\stackrel{\ddot{\bar{\alpha}}}{\bar{\alpha}} \\
\stackrel{\dot{p}}{\tilde{f}} \\
\end{array}$ & 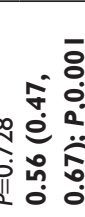 & o & \\
\hline & 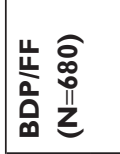 & & 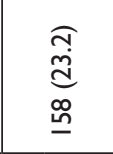 & 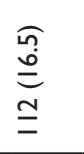 & $\begin{array}{l}0 \\
\dot{0} \\
\dot{y} \\
y\end{array}$ & 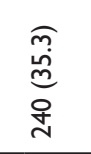 & $\begin{array}{l}\underset{\mathfrak{d}}{d} \\
\underline{o}\end{array}$ & 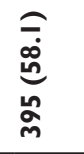 & 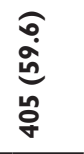 & 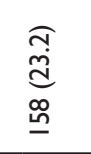 & 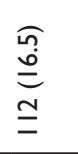 & $\begin{array}{l}0 \\
e \\
e \\
\dot{q} \\
\dot{y}\end{array}$ & $\begin{array}{l}\widehat{T} \\
\stackrel{d}{d} \\
\frac{a}{4}\end{array}$ & $\begin{array}{l}\widehat{o} \\
\stackrel{a}{d} \\
\frac{o}{+} \\
\underline{q}\end{array}$ & $\begin{array}{l}\underset{\sigma}{d} \\
\stackrel{0}{-}\end{array}$ & 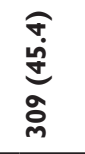 & 1 & \\
\hline 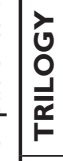 & 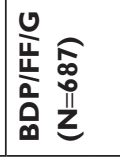 & & 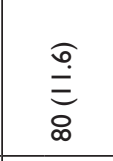 & $\begin{array}{l}\stackrel{\infty}{\mathcal{D}} \\
\stackrel{\infty}{\infty} \\
\infty\end{array}$ & $\stackrel{\alpha}{\rho}$ & $\begin{array}{l}a \\
\frac{a}{m} \\
\frac{5}{N}\end{array}$ & $\begin{array}{l}\stackrel{0}{d} \\
\dot{I} \\
\end{array}$ & 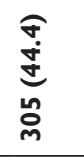 & $\begin{array}{l}\hat{d} \\
\text { do }\end{array}$ & 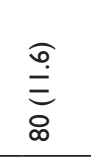 & 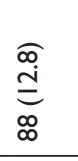 & $\begin{array}{l}\hat{\sigma} \\
\stackrel{n}{n} \\
\hat{i}\end{array}$ & 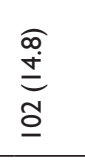 & 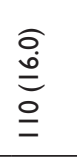 & $\begin{array}{l}\widehat{O} \\
\stackrel{d}{ \pm} \\
\stackrel{ \pm}{-}\end{array}$ & 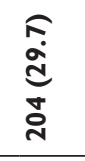 & $\widehat{m}$ & \\
\hline \% & & & 胥 & 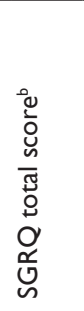 & 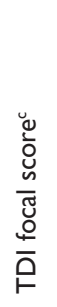 & 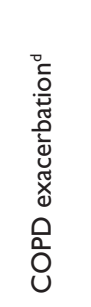 & 吂 & 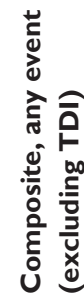 & 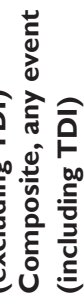 & 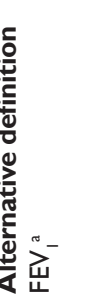 & 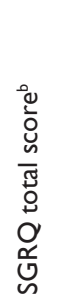 & 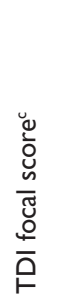 & 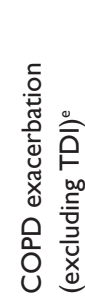 & 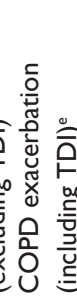 & $E D^{\circ}$ & 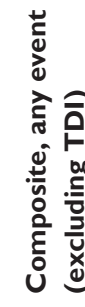 & 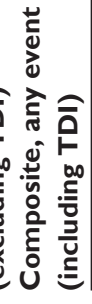 & \\
\hline
\end{tabular}




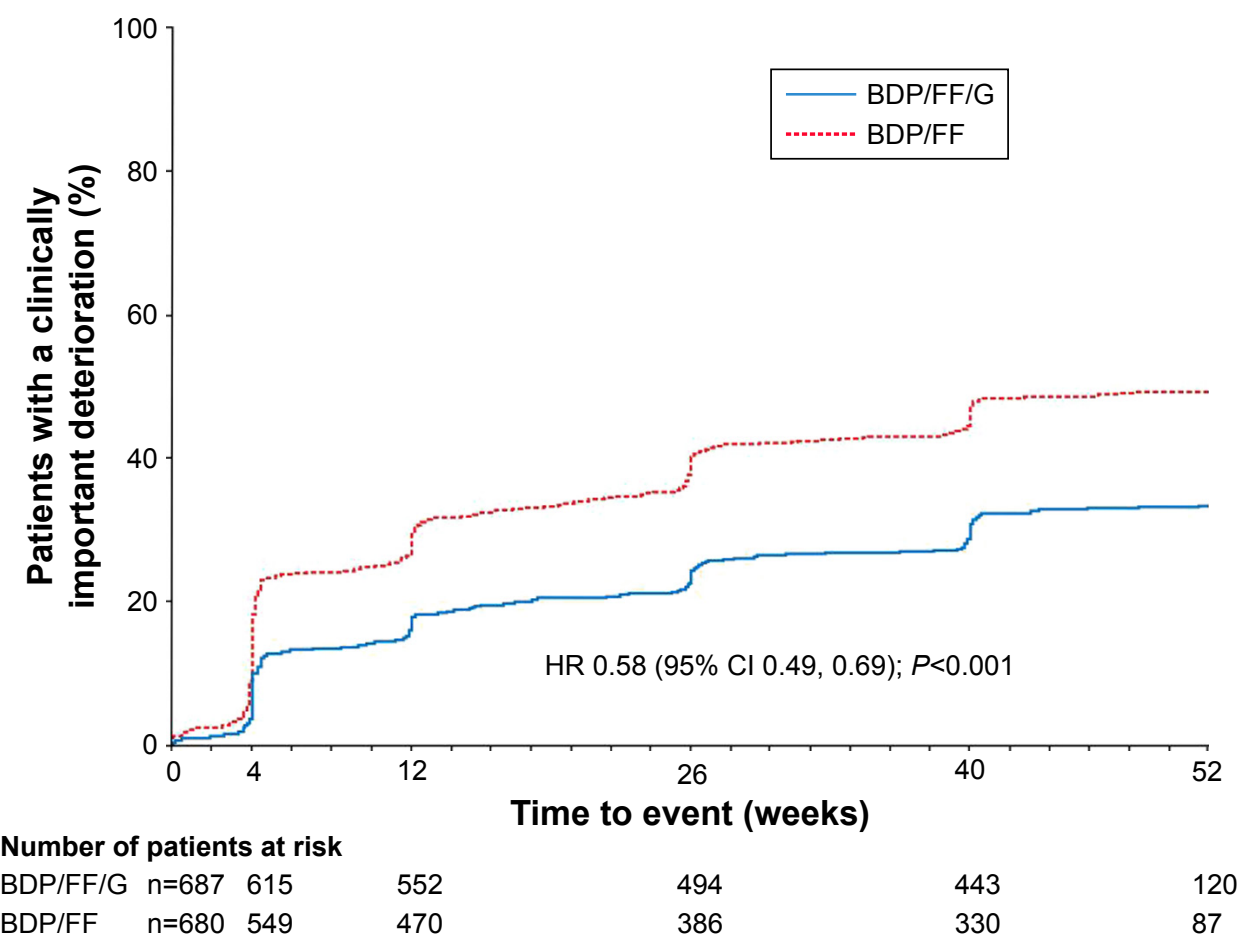

Figure S2 TRILOGY: Time to sustained CID (with TDI), alternative definition.

Notes: Time to sustained CID was defined as: a CID in FEV , and/or SGRQ total score and/or TDI focal score maintained at all subsequent visits; a moderate/severe exacerbation followed by a CID in FEV, and/or SGRQ total score and/or TDI focal score at all subsequent visits, or the exacerbation resulted in study discontinuation, or they had at least one further exacerbation; or death.

Abbreviations: CID, clinically important deterioration; BDP, beclometasone dipropionate; FF, formoterol fumarate; G, glycopyrronium; TDI, Transition Dyspnea Index; SGRQ, St George's Respiratory Questionnaire.

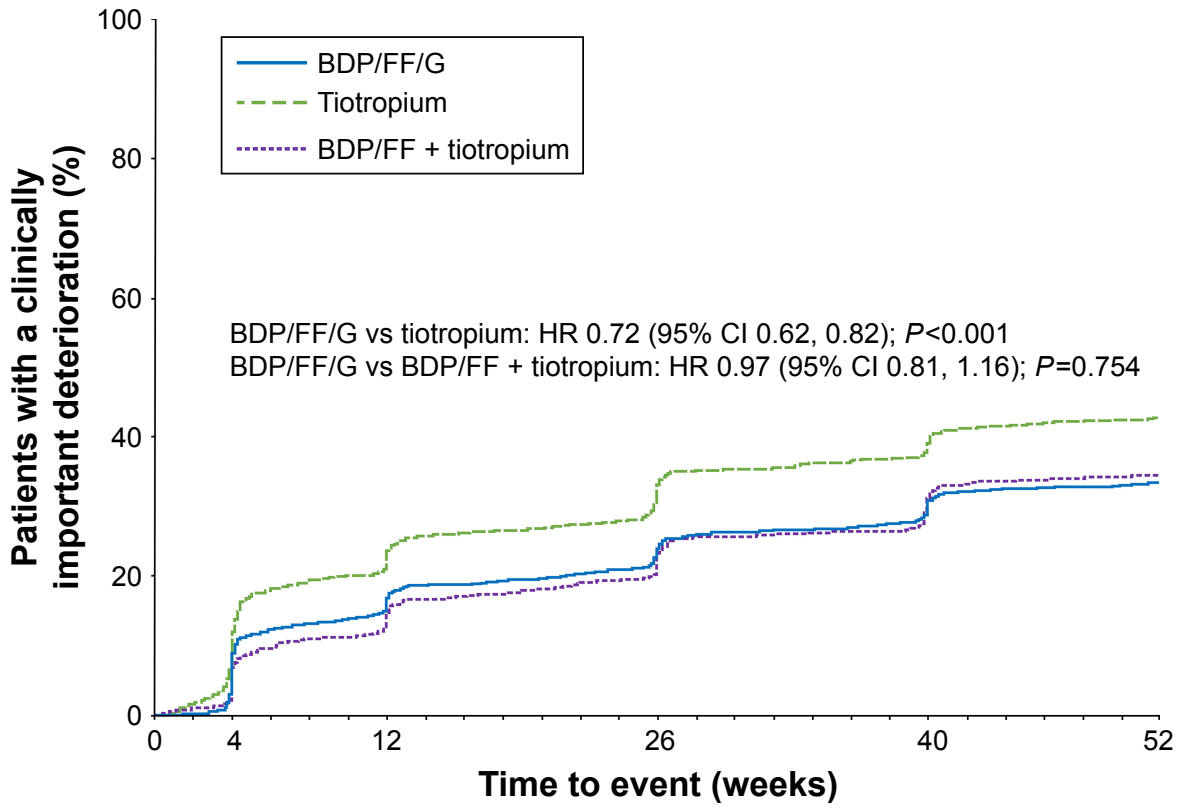

\section{Number of patients at risk}

$\begin{array}{lllllll}\text { BDP/FF/G } & \mathrm{n}=1,077 & 968 & 871 & 786 & 708 & 201 \\ \text { Tiotropium } & \mathrm{n}=1,074 & 926 & 781 & 666 & 596 & 186 \\ \text { BDP/FF + tio } & \mathrm{n}=538 & 498 & 453 & 399 & 353 & 106\end{array}$

Figure S3 TRINITY: Time to sustained CID, alternative definition.

Notes: Time to sustained CID was defined as: a CID in FEV, and/or SGRQ total score maintained at all subsequent visits; a moderate/severe exacerbation followed by a CID in FEV, and/or SGRQ total score at all subsequent visits, or the exacerbation resulted in study discontinuation, or they had at least one further exacerbation; or death. Abbreviations: CID, clinically important deterioration; BDP, beclometasone dipropionate; FF, formoterol fumarate; G, glycopyrronium; SGRQ, St George's Respiratory Questionnaire. 


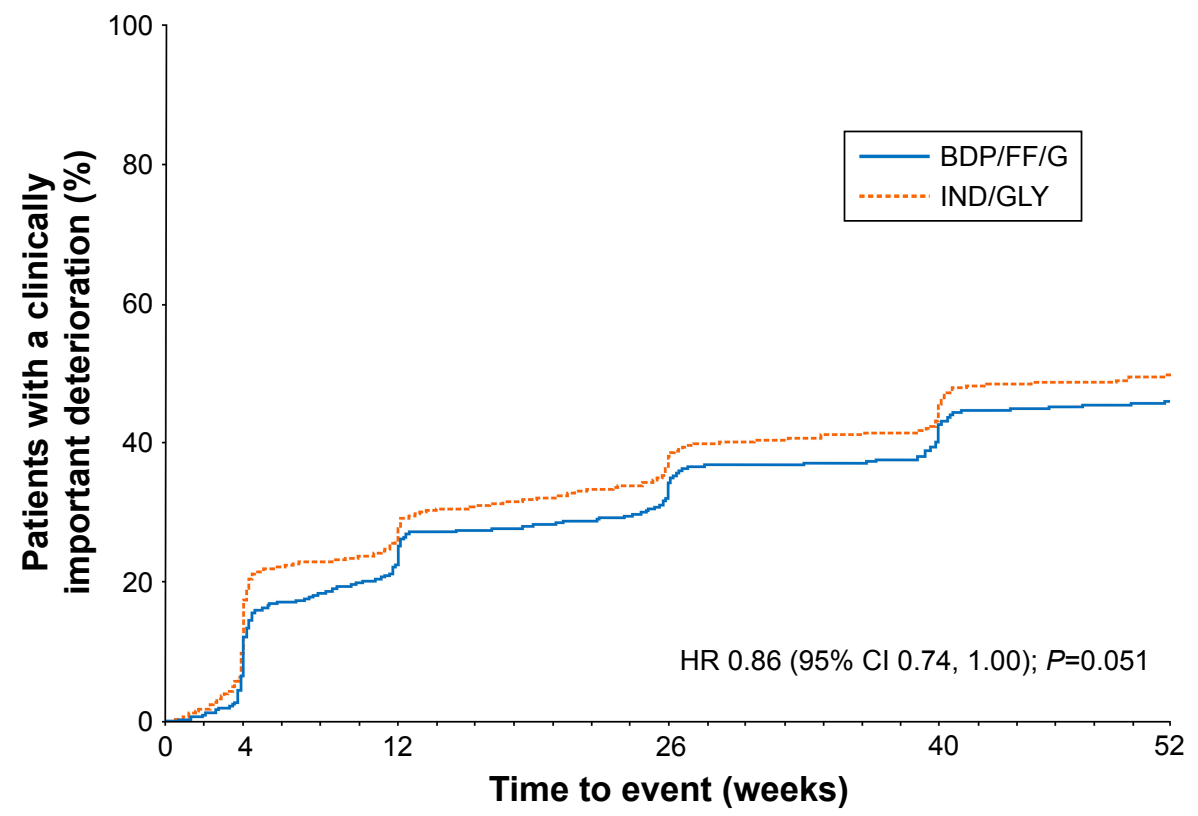

Number of patients at risk

$\begin{array}{lllllll}\text { BDP/FF/G } & \mathrm{n}=764 & 706 & 580 & 491 & 428 & 242 \\ \text { IND/GLY } & \mathrm{n}=768 & 690 & 554 & 458 & 399 & 244\end{array}$

Figure S4 TRIBUTE: Time to sustained CID, alternative definition.

Notes: Time to sustained CID was defined as: a CID in FEV, and/or SGRQ total score maintained at all subsequent visits; a moderate/severe exacerbation followed by a CID in FEV and/or SGRQ total score at all subsequent visits, or the exacerbation resulted in study discontinuation, or they had at least one further exacerbation; or death. Abbreviations: CID, clinically important deterioration; BDP, beclometasone dipropionate; FF, formoterol fumarate; G, glycopyrronium; IND/GLY, indacaterol/ glycopyrronium; SGRQ, St George's Respiratory Questionnaire.

\section{Publish your work in this journal}

The International Journal of COPD is an international, peer-reviewed journal of therapeutics and pharmacology focusing on concise rapid reporting of clinical studies and reviews in COPD. Special focus is given to the pathophysiological processes underlying the disease, intervention programs, patient focused education, and self management protocols.
This journal is indexed on PubMed Central, MedLine and CAS. The manuscript management system is completely online and includes a very quick and fair peer-review system, which is all easy to use. Visit $\mathrm{http} / / / \mathrm{www}$.dovepress.com/testimonials.php to read real quotes from published authors. 